\title{
Segmentasi pembuluh darah pada citra retina dengan menggunakan Multi-Scale Line Detector (MSLD) dan Adaptive Morphology
}

\author{
Adithya Kusuma Whardana a, Deni Sutaji ${ }^{b}$ \\ a Ilmu Komputer, STIMIK ESQ, Jakarta, Indonesia \\ ${ }^{b}$ Teknik Informatika, Universitas Muhammadiyah Gresik, Gresik, Indonesia \\ email:aadithya.kusuma@esqbs.ac.id,bsutaji.deni@gmail.com
}

\begin{tabular}{l}
\hline I N F O A R T I K E L \\
\hline Sejarah artikel: \\
Menerima 6 Februari 2017 \\
Revisi 23 Desember 2017 \\
Diterima 23 Desember 2017 \\
Online 24 Desember 2017 \\
\hline
\end{tabular}

Kata kunci:

Adaptive Morphology

Multi-Scale Line Detector

Optic disc

Pembuluh darah

Segmentasi

Keywords:

Adaptive morphology

Blood vessels

Multi-Scale Line Detector

Optic disc

Segmentation

Style APA dalam mensitasi artikel ini:

Whardana, A. K., \& Sutaji, D. (2017). Segmentasi pembuluh darah pada citra retina dengan menggunakan Multi-Scale Line Detector (MSLD) dan Adaptive Morphology. Register: Jurnal Ilmiah Teknologi Sistem Informasi, 3(1), 49-56.

\begin{abstract}
A B S T R A K
Pembuluh darah pada retina merupakan bagian retina yang berfungsi memberikan suplai darah dan oksigen ke dalam retina. Sehingga apabila pembuluh darah tidak tersuplai oksigen, maka dapat ditarik kesimpulan bahwa pembuluh darah retina tersebut bermasalah, banyaknya noise pada daerah pembuluh darah menyebabkan proses dalam segmentasi. Karena permasalahan yang timbul, maka dalam penelitian ini diusulkan metode segmentasi pembuluh darah dengan menggabungkan dua metode, yaitu metode Multi-Scale Line Detector (MSLD) dan Adaptive Morphology. Dari keseluruhan metode memiliki fungsi yang berbeda-beda, MSLD berfungsi dalam proses pemisahan garis yang dibentuk oleh pembuluh darah yang dalam hal ini melalui proses perubahan citra orisinal ke citra green channel, namun dalam proses sebenarnya metode MSLD kurang dalam proses segmentasi, karena timbulnya masalah disaat terjadi garis yang menyilang antara optic disc dan pembuluh darah, sehingga pada saat segmentasi garis yang menyilang tersebut tidak akan ikut disegmentasi, sehingga membutuhkan metode penambahan pada proses segmentasinya, untuk itu diperlukan metode Adaptive Morphology, sehingga saat proses segmentasi sebelumnya yang telah dilakukan dengan menggunakan MSLD bisa disempurnakan dengan menggunakan metode Adaptive Morphology. Penggabungan metode sangat efektif karena bisa menghilangkan area optic disc yang membentuk garis menyilang dengan pembuluh darah secara sempurna dengan tanpa menghilangkan area pembuluh darah, sehingga dalam proses segmentasi dapat menghasilkan tingkat akurasi 97,94\%.
\end{abstract}

\section{A B S T R A C T}

The blood vessels of the retina are part of the retina that serves to supply blood and oxygen to the retina. So if the blood vessels are not supplied oxygen, it can be concluded that the retinal blood vessels are problematic, the amount of noise in the blood vessel causes the process in segments.Karena problems arise, then in this study proposed method of blood vessel segmentation by combining two methods, namely Methods of Multi-Scale Line Detector (MSLD) and adaptive morphology. From the whole method has different functions, MSLD function in the process of separation of lines formed by blood vessels in this case through the process of changing the original image to the green channel image, but in the actual process of MSLD method is less In the process of segmentation, due to the emergence of the problem when there is a crossing line between the optic disc and blood vessels, so that when the segmentation of the crossed line will not participate in segmentation, thus requiring additional method in the process of segmentation, for that required adaptive morphology method, Previous segmentation that has been done by using MSLD can be enhanced by using adaptive morphology method. Combination method is very effective because it can eliminate the optic disc area that forms a line crossed with blood vessels perfectly without removing the blood vessel area, so in the process of segmentation can produce an accuracy of $97.94 \%$.

(c) 2017 Register: Jurnal Ilmiah Teknologi Sistem Informasi. Semua hak cipta dilindungi undang-undang. 


\section{Pendahuluan}

Pembuluh darah merupakan salah satu bagian dari retina yang memiliki fungsi untuk suplai darah dan oksigen ke dalam jaringan retina (Whardana \& Suciati, 2014). Jika dalam suplai darah dan oksigen tidak lancar, maka hal ini dapat dijadikan acuan untuk mendeteksi apakah ada gangguan kesehatan (hipertensi, cardiovascular, strok atau diabetes). Untuk mendeteksi pembuluh darah yang memiliki masalah tersebut dapat dilakukan dengan segmentasi pembuluh darah pada citra digital retina. Telah banyak pendekatan yang dilakukan untuk menangani segmentasi pembuluh darah (supervised dan unsupervised), salah satunya adalah penelitian Sutaji, Fatichah, dan Navastara (2016) yang mengusulkan untuk mengurangi over-segmentation pada area patologi khususnya exudate pada citra fundus retina, tetapi masih belum memenuhi permasalahan state-of-the-art Nguyen, Bhuiyan, Park, dan Ramamohanarao (2013): a) Adanya refleksi cahaya dari pusat; b) Pembuluh darah; c) Percabangan pembuluh darah; d) Penggabungan pembuluh darah yang berdekatan; e) Kehilangan pembuluh darah yang tipis/kecil; e) Kesalahan deteksi pembuluh darah di wilayah; dan f) Optic dan patologis.

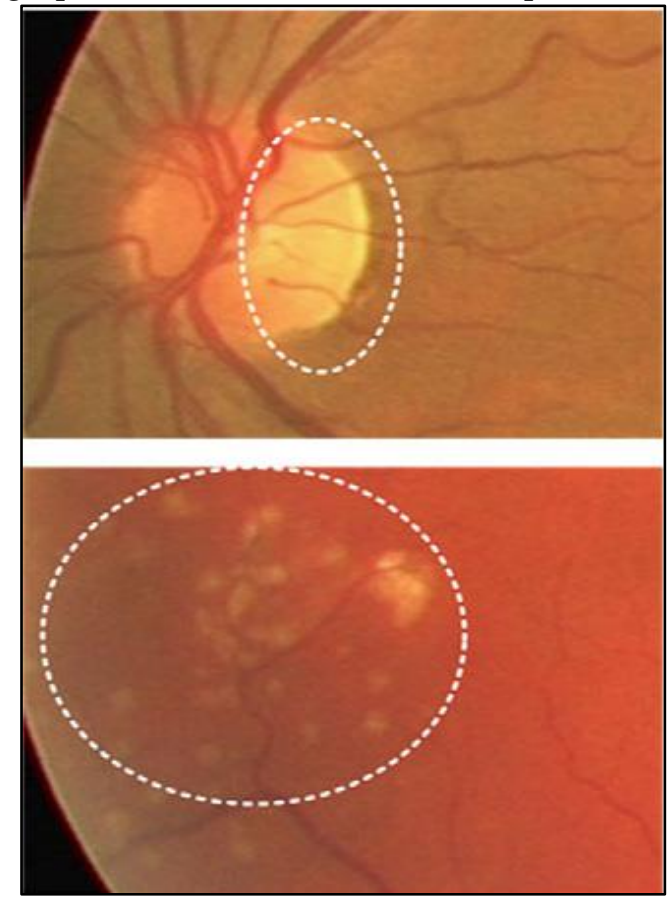

(a)
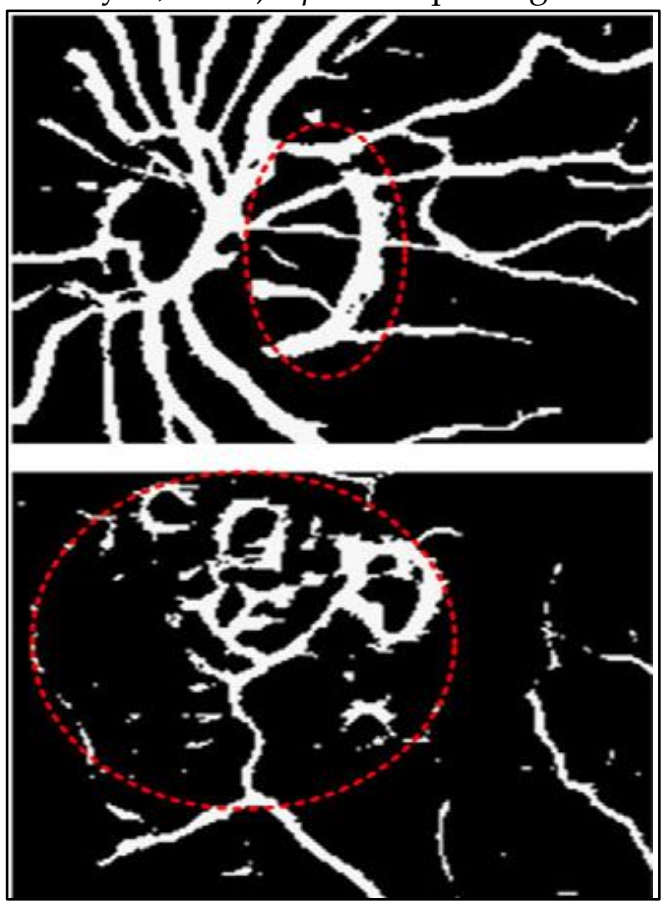

(b)

Gambar 1. Hasil penelitian Nguyen, Bhuiyan, Park, dan Ramamohanarao (2013): (a) Atas: Area optic disc, bawah: Pathological region; dan (b) Atas: Kesalahan segmentasi pada daerah optic disc, bawah: Kesalahan segmentasi pada pathological region.

Sedangkan 3 bagian yang menjadi faktor penting untuk memberikan dampak yang bagus pada vascular network, yaitu Nguyen, Bhuiyan, Park, dan Ramamohanarao (2013) : a) Jika pusat piksel reflek tidak terdeteksi sebagai bagian dari pembuluh darah, maka bisa dikenali sebagai 2 pembuluh darah; b) Jika 2 buah pembuluh darah menyatu, maka dianggap sebagai 1 pembuluh darah; dan c) Adanya percabangan pembuluh darah yang terputus.

Segmentasi diperlukan untuk memisahkan area optic disc dengan pembuluh darah, agar area yang ada di daerah optic disc pada saat disegmentasi tidak dianggap pembuluh darah (Welfer, et al., 2010). Multi-scale merupakan salah satu metode untuk proses segmentasi yang memisahkan pembuluh darah yang berdekatan, karena adanya optic disc pada area pembuluh darah, sehingga setelah disegmentasi dengan menggunakan multi-scale, area optic disc akan dianggap sebagai pembuluh darah, proses tersebut menyebabkan segmentasi pembuluh darah tidak sempurna. Hasil dari penelitian Nguyen, Bhuiyan, Park, dan Ramamohanarao (2013) ditunjukkan pada Gambar 1, Gambar 1 menunjukkan bahwa area optic disc yang menyatu dengan pembuluh darah dianggap pembuluh darah karena pada saat proses segmentasi citra orisinal diubah menjadi citra green channel, sehingga hanya menampakkan warna hitam dan putih, putih merupakan hasil dari pembuluh darah dan optic disc, menjadikan proses segmentasi pembuluh darah pada area optic disc tidak berhasil dengan sempurna 
(Nguyen, Bhuiyan, Park, \& Ramamohanarao, 2013) metode Multi-Scale Line Detector (MSLD)
segmentasi area pembuluh darah, tetapi dengan menggunakan metode tersebut, area optic disc tidak bisa disegmentasi karena dianggap garis putih, yang sama dengan area pembuluh darah yang akan di segmentasi, Welfer dkk (2010) menjelaskan bahwa penelitian ini menggunakan adaptasi morfologi dalam segmentasi pembuluh darah, pembuluh darah bisa berhasil dengan sempurna akan tetapi masih meninggalkan garis di area optic disc, yang seharusnya optic disc ikut dalam proses segmentasi. Seperti pada Gambar 1, bahwa area optic masih terlihat sangat jelas saat menggunakan metode MSLD.

Meskipun sudah banyak literatur yang membahas metode segmentasi untuk pembuluh darah retina ini, namun berbagai permasalahan masih terbuka untuk diteliti. Di antara permasalahanpermasalahan yang dihadapi adalah: a) Area pembuluh darah yang bersilangan dengan area lain; $b$ ) Adanya perpotongan pembuluh darah dengan optic disc; dan c) Banyaknya noise pada area pembuluh darah.

\section{Metode Penelitian}

Ide utama dari metode yang diusulkan adalah bagaimana menggabungkan 2 (dua) metode untuk segmentasi citra, melakukan proses segmentasi sehingga menghasilkan segmentasi citra yang lebih akurat. Gambar 2 menggambarkan dari urutan alur proses metode yang dilakukan dalam penelitian ini.

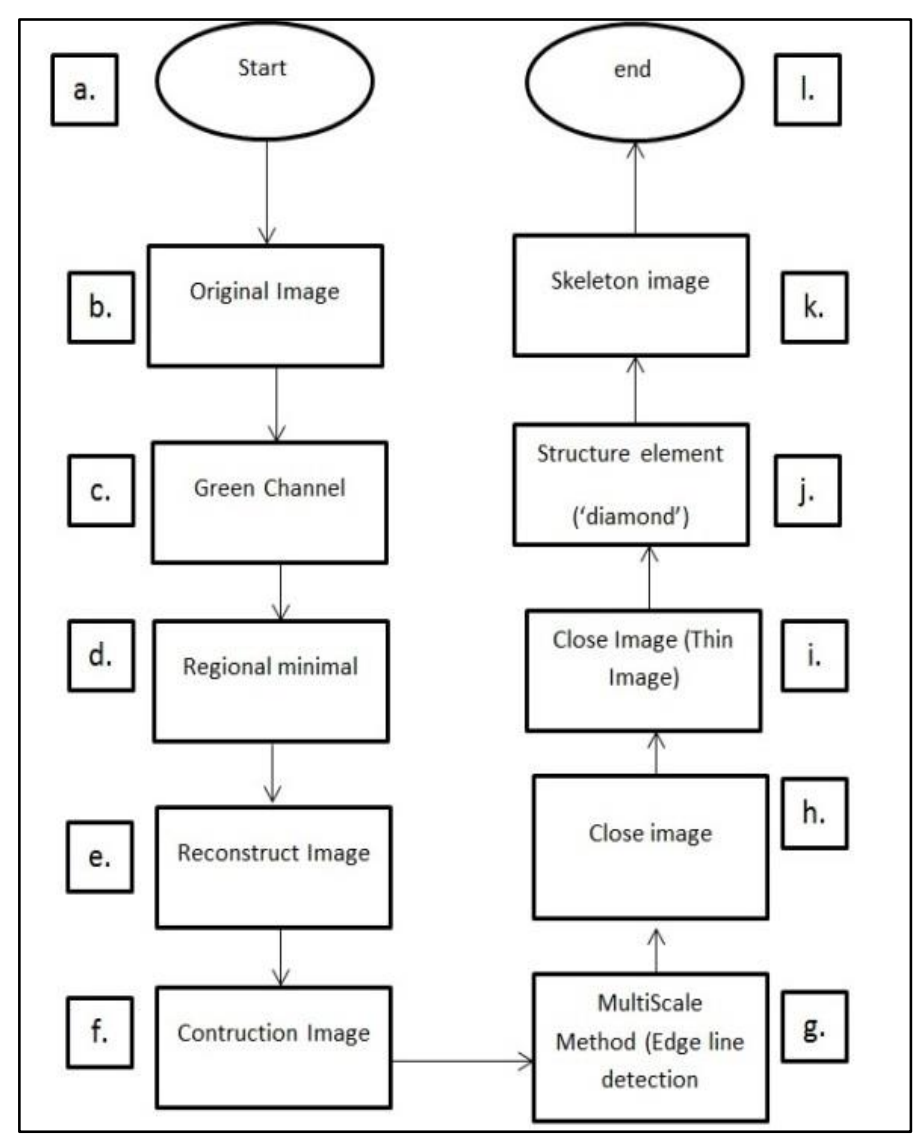

Gambar 2. Usulan Metode dalam Penelitian ini

Gambar 2.b merupakan proses awal dari proses segmentasi yang dilakukan dalam penelitian ini, citra asli dari retina diproses, kemudian citra asli akan diubah ke citra beraras keabuan, kemudian pada langkah selanjut citra yang telah diubah, akan direkonstruksi ulang dengan menggunakan operasi morfologi, pada langkah a-f, h-i merupakan segmentasi yang menggunakan metode Adaptive Morphology, pada langkah g.

Proses segmentasi akan dikombinasi dengan metode MSLD, agar dalam proses segmentasi berikutnya garis putih yang membentuk seperti pembuluh darah akan dihilangkan karena dianggap noise, kemudian pada langkah berikutnya segmentasi citra yang telah diproses akan dilakukan proses 

menggunakaan close image dengan operasi thin image, sehingga pembuluh darah yang tebal akan ditipiskan agar bisa diproses menggunakan struktur elemen dengan menggunakan operasi "diamond" Adaptive Morphology, langkah terakhir yang akan dilakukan dengan menggunakan operasi skeleton Adaptive Morphology, yang berfungsi untuk menyambungkan garis yang merupakan pembuluh darah yang terputus saat proses segementasi sebelumnya.

\subsection{Multi-Scale Line Detector (MSLD)}

Metode yang diusulkan untuk segmentasi pertama adalah multi-scale, multi-scale berfungsi untuk menghaluskan pembuluh darah pada daerah vascular tree dan pada daerah pembuluh darah (Nguyen, Bhuiyan, Park, \& Ramamohanarao, 2013). Pembuluh darah pada retina terdiri dari arteri dan vena (Fraz, et al., 2011). Segmentasi retina menggunakan multi-scale untuk memperjelas gambar pada area pembuluh darah tersebut (Fraz, et al., 2011). Dalam proses segmentasi ini akan dilakukan dengan menggunakan database dari DRIVE. Multi-scale sebenarnya adalah sebuah proses perhitungan. Pendekatan pada area pembuluh darah, sehingga multi-scale melakukan tugas segmentasi pada resolusi gambar yang berbeda dan ukuran struktur yang sebenarnya dengan menggunakan citra asli yang telah diubah ke citra bearas keabuan.

Tujuan dari metode ini adalah menghaluskan area pembuluh darah yang saling berdekatan dan membuat lebih jelas pada area optic disc dan pembuluh darah, sehingga pada area optic disc pada retina tidak dianggap sebagai pembuluh darah. Karakteristik dari metode multi-scale adalah mendeteksi semua garis, tapi kelemahan dari metode ini, apabila ada garis yang bersilangan maka garis tersebut tidak bisa disegmentasi dengan baik oleh metode, maka apabila ada optic disc yang bersilangan dengan pembuluh darah maka garis tersebut tidak ikut proses segmentasi. Dalam proses segmentasi citra retina harus diubah ke citra bearas keabuan supaya memudahkan dalam proses segmentasi, untuk menyempurnakan proses segmentasi maka metode multi-scale ini digabungkan dengan metode Adaptive Morphology yang berguna untuk menyempurnakan proses segmentasi.

\subsection{Edge detection}

Edge detection merupakan teknik deteksi tepi citra pembuluh darah retina dengan memisahkan yang dalam prosesnya citra retina orisinal diubah terlebih dahulu ke area green channel, sehingga proses deteksi tepi bisa dilakukan, yang di mana edge detection ini menggunakan teknik canny detection, canny berfungsi untuk menghaluskan deteksi tepi sehingga saat proses segmentasi berikutnya bisa berhasil (Thirumavalavan \& Jayaraman, 2016).

\subsection{Adaptive Morphology}

Metode yang diusulkan dalam perbaikan segmentasi citra retina pada penelitian ini menggunakan database citra retina DRIVE, STARE dan REVIEW (Welfer, et al., 2010). Metode ini untuk menyempurnakan hasil segmentasi dari MSLD, sehingga pada area optic disc tidak dideteksi sebagai area pembuluh darah.

Gambar retina yang sudah tersegmentasi sebelumnya dengan metode MSLD, diperbaiki lagi dengan menggunakan metode Adaptive Morphology. Penulis mengusulkan metode morfologi perbaikan pada penelitian sebelumnya (Welfer, et al., 2010). Ide dari metode ini adalah menghilangkan optic disc yang ada pada retina, sehingga optic disc tidak dianggap sebagai pembuluh darah, dan pada area yang dilalui oleh optic disc bisa terlihat bagus.

Pada proses sebelumnya dengan menggunakan menggunakan multi-scale area optic disc akan terlihat seperti garis, di mana garis tersebut sama seperti garis pembuluh darah, permasalahan pada metode sebelumnya, garis menyilang yang terbentuk oleh optic disc pada saat proses segmentasi dianggap pembuluh darah, maka proses tersebut disempurnakan dengan menggunakan metode morfologi, sehingga area optic disc tersebut bisa disegmentasi dengan sempurna, sehingga tidak ada lagi garis optic disc saat proses segmentasi selesai. Hasil segmentasi pada Gambar 4.d.

\section{Hasil dan Pembahasan}

Pada bagian ini, merupakan penjelasan dan uraian dari hasil pengujian penelitian dan pembahasan metode. Pengujian metode dilakukan dengan menggunakan database citra retina DRIVE. Langkah 
pertama yang dilakukan adalah merubah citra asli ke citra green channel, yang diambil dari database DRIVE. Hasil pengujian dengan menggunakan penggabungan dua metode ini dapat menambah akurasi segmentasi $97,94 \%$.

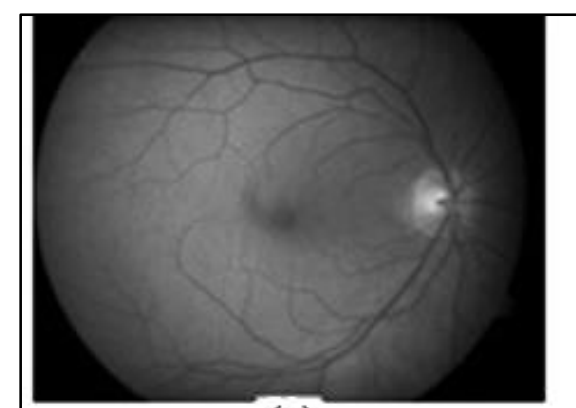

(a)

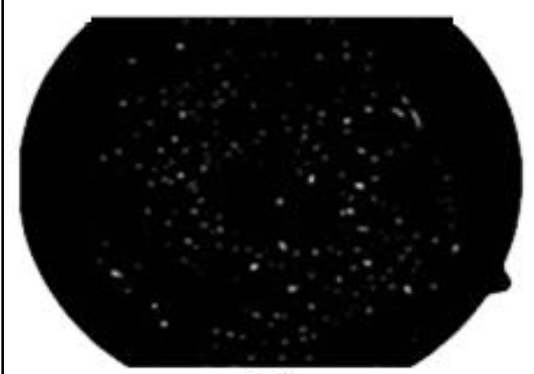

(c)

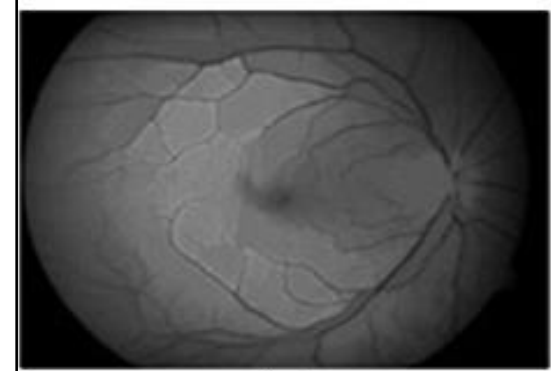

(e)

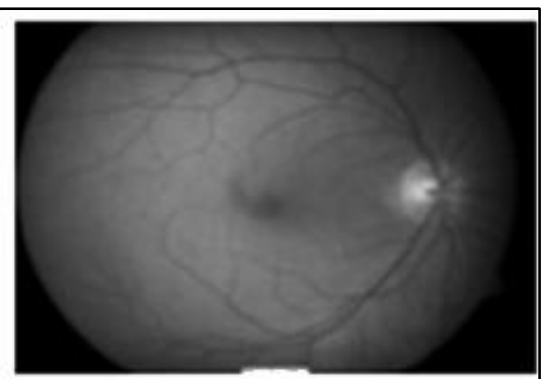

(b)

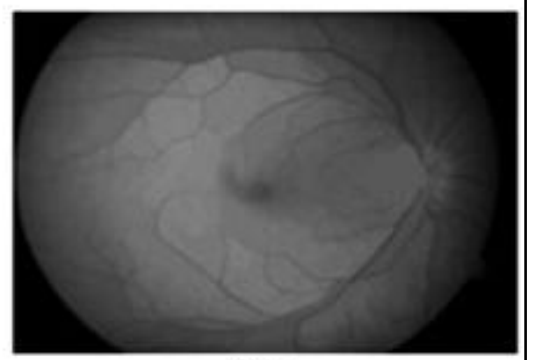

(d)

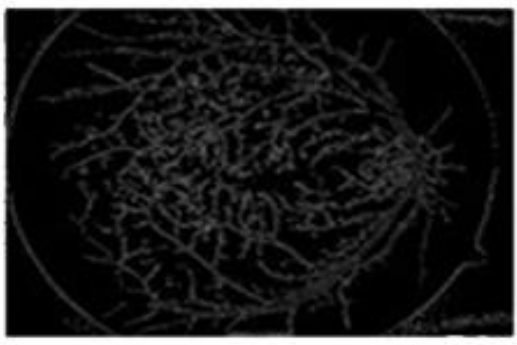

(f)

Gambar 3. Hasil multi-scale: (a) Gambar citra abu-abu; (b) Filtering image; (c) Regional minimal; (d) Rekonstruksi citra; (e) Konstruksi citra; dan (f) Edge detection.

Metode yang diusulkan pada makalah ini adalah menggabungkan metode multi-scale dan metode Adaptive Morphology. Kedua metode tersebut digabungkan sehingga akan menjadi hasil segmentasi yang lebih bagus dari penelitian sebelumnya.

Langkah dari penggabungan kedua metode tersebut adalah:

1. Citra retina asli dijadikan citra abu-abu, hasil ditunjukkan pada Gambar 3.a.

2. Citra abu-abu kemudian dilakukan filtering image, hasil ditunjukkan pada Gambar 3.b.

3. Setelah citra retina dilakukan filter, selanjutnya dilakukan regional minimal. Hasil ditunjukkan pada Gambar 3.c.

4. Langkah keempat dilakukan rekonstruksi citra. Hasil ditunjukkan pada Gambar 3.d.

5. Langkah selanjutnya dilakukan konstruksi citra retina. Hasil ditunjukkan pada Gambar 3.e.

6. Kemudian langkah selanjutnya, proses metode multi-scale menggunakan edge detection dan line detection. Hasil uji coba ditunjukkan pada Gambar 3.f.

7. Langkah selanjutnya dilakukan closing image. Hasil uji coba ditunjukkan pada Gambar 4.a.

8. Langkah selanjutnya dilakukan closing citra kurus pada citra retina. Hasil ditunjukkan pada Gambar 4.b.

9. Langkah berikutnya adalah penyisipan metode Adaptive Morphology. Melakukan proses struktur element dengan menggunakan fungsi "diamond". Hasil ditunjukkan pada Gambar 4.c.

10. Proses berikutnya dilakukan proses skeleton image. Hasil ditunjukkan pada Gambar 4.d. 

yang telah dilakukan multi-scale pada tahap terakhir ini bisa jelas dan pada area optic disc tidak ada area yang seharusnya area optic disc dianggap pembuluh darah. Hasil ditunjukkan pada Gambar 4.e.

Gambar 3 merupakan hasil dari keseluruhan proses kombinasi dua metode yang telah dilakukan dengan menggunakan kombinasi metode MSLD dan Adaptive Morphology.

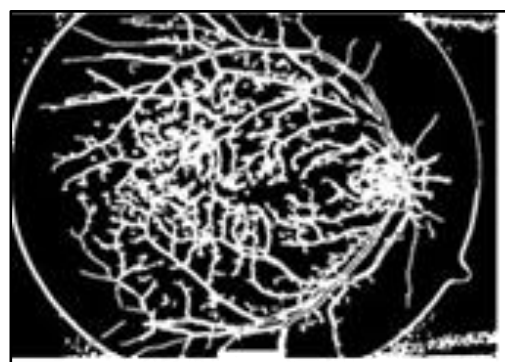

(a)

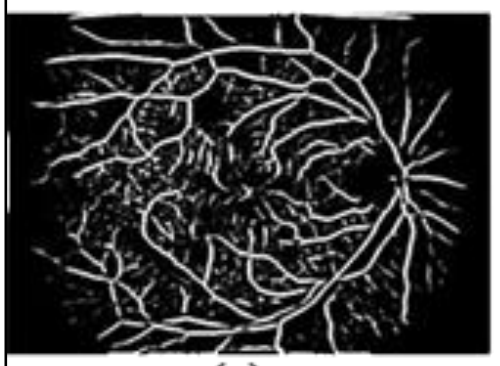

(c)

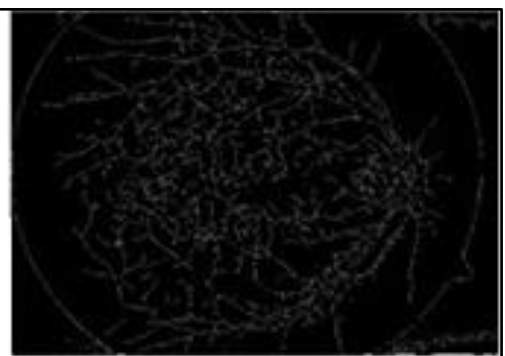

(b)

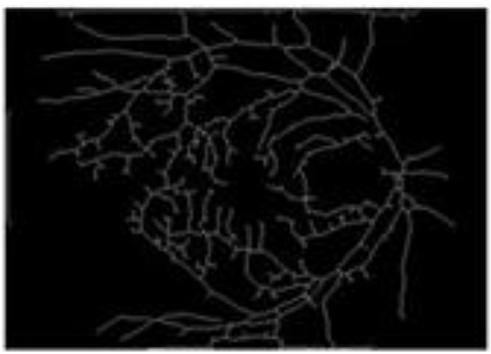

(d)

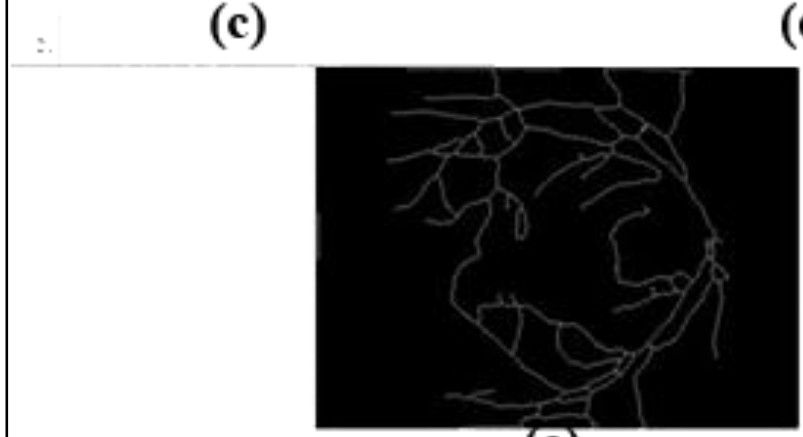

(e)

Gambar 4. Hasil Adaptive Morphology: (a) Close image; (b) Close image (thin image); (c) Struktur element; (d) Skeleton image; dan (e) Pruning image

\section{Evaluasi Metode}

Pada metode sebelumnya hanya menggunakan metode multi-scale, sehingga hasil tidak maksimal pada area optic disc yang dianggap sebagai pembuluh darah, sehingga optic disc tidak ikut tersegmentasi, karena dianggap sebagai pembuluh darah, hasil metode sebelumnya ditunjukkan pada Gambar 5. Metode baru yang diusulkan menggabungkan 2 metode MSLD dan Adaptive Morphology ini menghilangkan area optic disc yang dianggap pembuluh darah dengan tingkat akurasi 97,94\%. 

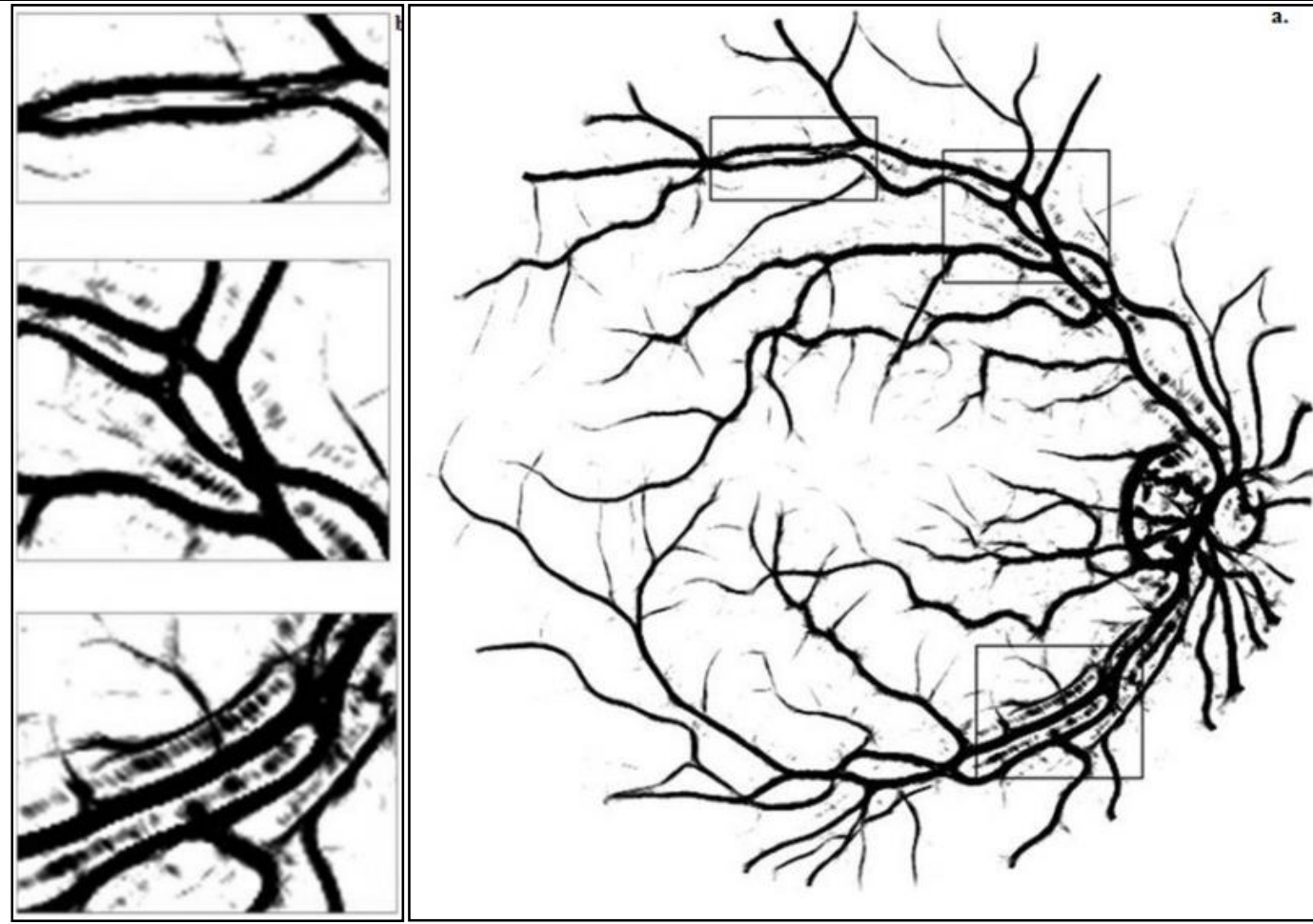

(a)

(b)

Gambar 5. Hasil penelitian sebelumnya: (a) Hasil multiscale; (b) Area optic disk yang dianggap pembuluh darah

\section{Kesimpulan}

Dalam penelitian ini diusulkan metode baru untuk segmentasi pada retina. Penelitian ini menggunakan metode MSLD dan Adaptive Morphology. Ide ini untuk mensegmentasi daerah optic disc menggunakan penggabungan dua metode, metode ini menghasilkan segmentasi yang bagus, sehingga area optic disc pada retina tidak terdeteksi sebagai pembuluh darah tidak terpotong, dan pada area pembuluh darah lebih jelas pada area ground-truth. Dalam pengujian ini berhasil mengimplementasikan citra retina yang lebih baik dari peneliti sebelumnya, pada peneliti sebelumnya menggunakan multi-scale tidak bisa menghilangkan area optic disc (Nguyen, Bhuiyan, Park, \& Ramamohanarao, 2013) hasil sebelumnya dievaluasi metodenya. Pada penelitian ini penulis berhasil menghilangkan area optic disc.

\section{Ucapan Terima Kasih}

Tim peneliti berterima kasih kepada dosen pengampu, yang dengan sabar mengajari penulis, sehingga makalah ini bisa terbentuk, karena atas do'a dan bimbingan beliau bapak Dr. Agus Zainal Arifin, S.Kom, M.Kom dan ibu Diana Purwitasari, S.Kom, M.Sc.

\section{Referensi}

Fraz, M. M., Remagnino, P., Hoppe, A., Velastin, S., Uyyanonvara, B., \& Barman, S. A. (2011). A supervised method for retinal blood vessel segmentation using line strength, multiscale Gabor and morphological features. Signal and Image Processing Applications (ICSIPA), 2011 IEEE International Conference on (pp. 410-415). Kuala Lumpur: IEEE.

Nguyen, U. T., Bhuiyan, A., Park, L. A., \& Ramamohanarao, K. (2013). An effective retinal blood vessel segmentation method using multi-scale line detection. Pattern Recognition, 46(3), 703-715.

Sutaji, D., Fatichah, C., \& Navastara, D. A. (2016). Segmentasi Pembuluh Darah Retina Pada Citra Fundus Menggunakan Gradient Based Adaptive Thresholding Dan Region Growing. Register: Jurnal Ilmiah Teknologi Sistem Informasi, 2(2), 105-116.

Thirumavalavan, S., \& Jayaraman, S. (2016). An improved teaching-learning based robust edge detection algorithm for noisy images. Journal of Advanced Research, 7(6), 979-989. 

Segmentation of the optic disk in color eye fundus images using an adaptive morphological approach. Computers in Biology and Medicine, 40(2), 124-137.

Whardana, A. K., \& Suciati, N. (2014). A Simple Method for Optic Disk Segmentation from Retinal Fundus Image. International Journal of Image, Graphics and Signal Processing, 6(11), 36-42. 